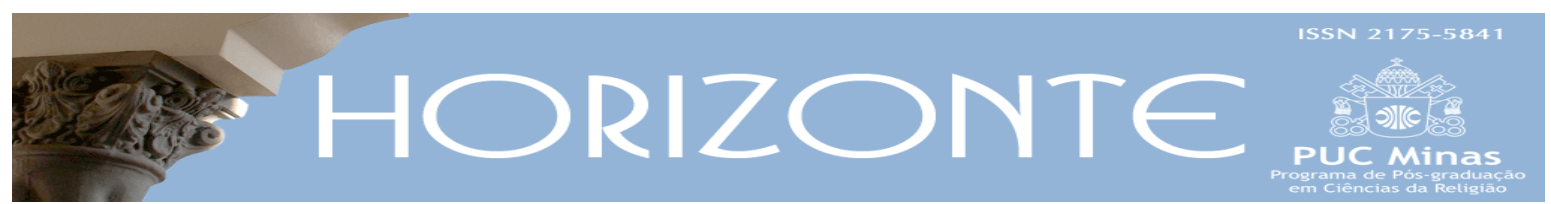

Dossiê: Fundamentalismos e Democracia - Artigo Original (C) (1)

\title{
Evangélicos fundamentalistas e política: uma análise da conjuntura brasileira (2018-2019)
}

\author{
Fundamentalist evangelicals and politics: \\ an analysis of the Brazilian situation (2018-2019)
}

Breno Martins Campos *

\begin{abstract}
Resumo
Este artigo reconhece que nunca se falou tanto em fundamentalismo em nosso país como agora; e que o uso ampliado do conceito poucas vezes vem associado ao espectro do protestantismo definido pela hermenêutica literal das Escrituras, como nos primórdios do movimento fundamentalista. No Brasil contemporâneo, grosso modo, fundamentalista qualifica o evangélico conservador ou reacionário, quase sempre pentecostal, e com inserção na mídia e na política. Assim, é urgente que a ação de evangélicos fundamentalistas no espaço público-político brasileiro seja compreendida pelas Ciências da Religião (em diálogo com a Teologia), uma vez que coloca em questão a democracia ao transformar interesses religiosos particulares em questões de Estado e ações de governo. O objetivo deste artigo, portanto, é avaliar como o qualificativo fundamentalista associado ao nome evangélico contribui para a compreensão da eleição de Jair Bolsonaro à presidência da República em 2018, adotando como recorte o caso da promessa de mudança da embaixada brasileira em Israel de Tel Aviv para Jerusalém. As conclusões alcançadas acerca das imbricações do assim chamado sionismo cristão (como um traço fundamentalista de setores evangélicos) com a eleição de Bolsonaro resultam de pesquisa bibliográfica e documental, cujos dados empíricos foram retirados do jornal Folha de S. Paulo.
\end{abstract}

Palavras-chave: Evangélicos fundamentalistas. Sionismo cristão. Eleições. Brasil. Bolsonaro.

\begin{abstract}
This article acknowledges that fundamentalism has never been such a popular topic in Brazil as it is today; and that the wide use of the concept is rarely associated with the spectrum of Protestantism defined by the literal hermeneutics of the Scriptures, as in the onset of the fundamentalist movement. Roughly, in contemporary Brazil the adjective fundamentalist qualifies one that is a conservative or reactionary evangelical, usually Pentecostal, and with some presence in the media and politics. Thus, actions of fundamentalist evangelicals in the Brazilian public and political space must be understood by the Religious Studies (in dialogue with Theology), since democracy is at stake when particular religious interests are transformed into matters of State and governmental actions. Therefore, this article aims at assessing how the qualification "fundamentalist" associated with the name "evangelical" contributes to understand Jair Bolsonaro's election to the Presidency of the Republic in 2018, with a focus on his promise of changing the Brazilian embassy in Israel of Tel Aviv to Jerusalem. The conclusions on the relationship of the so-called Christian Zionism (as a fundamentalist feature of evangelical sectors) with the election of Bolsonaro result from bibliographical and documentary research, whose empirical data of were obtained from the Folha de S. Paulo newspaper.
\end{abstract}

Keywords: Fundamentalist evangelicals. Christian zionism. Elections. Brazil. Bolsonaro.

Artigo submetido em 11 de julho de 2020 e aprovado em 20 de dezembro de 2020.

* Doutor em Ciências Sociais pela PUC-SP. Professor da PUC-Campinas. País de origem: Brasil. E-mail: brenomartinscampos@gmail.com 


\section{Introdução}

O recorte histórico deste artigo privilegia acontecimentos específicos do entrelaçamento de evangélicos fundamentalistas com a política no Brasil, que se deram a partir do segundo semestre de 2018 na campanha eleitoral e resultaram na eleição de Jair Messias Bolsonaro (então filiado ao PSL e atualmente sem partido) à presidência da República, mas que, de fato, haviam começado antes. Em visada retrospectiva (e ampliada), sob o que ficou conhecido como "jornadas de junho" em 2013, o Brasil viveu um período - integrado à cena internacional -, cujas considerações intermediárias estão postas, mas as finais ainda estão longe de um esgotamento.

Para corroborar a discussão da inserção do caso brasileiro no cenário internacional, não em uma relação de causa e efeito, mas, antes, em um processo de concomitância, recorro a Boaventura de Sousa Santos e ao que ele batizou genericamente de "revoltas da indignação" (ocorridas de 2011 a 2013, em várias regiões do globo):

Claro que algumas lutas são anteriores. Na América Latina, por exemplo, várias resistências e lutas que levaram a um grande progresso ocorreram antes disso, com destaque para a primeira década do século XXI. Mas é interessante observar que, entre 2011 e 2013, em diferentes países e contextos - alguns muito surpreendentes -, houve uma onda de reivindicações populares, resistências e alternativas emergentes. Os protestos que tenho em mente são a Primavera Árabe no Norte da África e no Médio Oriente, o movimento Occupy Wall Street, que subsequentemente se expandiu para outras cidades americanas, o movimento dos indignados na Europa do Sul (Grécia, Portugal, Espanha e Itália), o movimento estudantil chileno de 2012, o movimento \#Yosoy132 contra a fraude eleitoral no México, e, por fim, em junho de 2013, os protestos maciços no Brasil contra o aumento das tarifas dos transportes públicos e a precariedade dos serviços públicos em geral. (SANTOS, 2018, p. 275-276)

A análise de conjuntura que proponho, a fim de compreender as relações entre evangélicos fundamentalistas e política no Brasil, portanto, dá-se ainda no calor da hora (2018 e 2019, com algumas entradas em 2020). Por sugestão do artigo "Bolsonaro presidente: conservadorismo, evangelismo e a crise brasileira", de Ronaldo de Almeida (2019), na seção em que o autor articula o desdobramento da crise nacional em temporalidades, também eu divido a conjuntura nacional em 
quatro períodos principais, cada qual com um acontecimento marcante, cujos desdobramentos estão vinculados e em pleno movimento: 2013 e os protestos de rua; 2014 e a reeleição de Dilma Rousseff; 2016 e o impeachment da presidente; e, por fim, 2018 e a eleição de Bolsonaro à presidência. Parece óbvio, mas não custa explicar que, embora a cronologia importe, os eventos não devem ser considerados em sequência linear, mas na interseção de uns com os outros. ${ }^{1}$

Adoto neste artigo o procedimento metodológico de não separar o trabalho de investigação - antes de tudo, iniciado por incômodo - e minha vida de pesquisador, à semelhança do que propõe Charles Wright Mills no apêndice "Do artesanato intelectual" do livro A imaginação sociológica. Pelo menos neste trabalho, quero me situar no legado do sociólogo estadunidense, uma vez que o tema do fundamentalismo faz parte de meu ofício por fazer parte de minha vida, mas quero também fazer transbordar o conceito da área da Sociologia para a das Ciências da Religião e Teologia.

Também concordo com Mills (1972, p. 239) quanto à ideia de que jamais se começa a trabalhar num projeto de pesquisa, mas, sim, que "já estamos 'trabalhando', seja num veio pessoal, nos arquivos, nas notas tomadas aos rascunhos, ou nos empreendimentos dirigidos". Mais recentemente, movido pelo senso de responsabilidade e urgência, passei a investigar como evangélicos fundamentalistas vêm ocupando cada vez mais espaço na cena pública e política no Brasil - e como essa mistura coloca em questão a democracia, por tentar transformar uma leitura literal da Bíblia e suas consequências, próprias da esfera religiosa e privada, em questões de Estado e ações de governo. Dentre muitos caminhos possíveis para debater a temática, optei pelo caso da promessa do candidato Bolsonaro à presidência de transferir a embaixada do Brasil em Israel de Tel Aviv para Jerusalém, a fim de atender ao anseio de parte considerável de seu

\footnotetext{
${ }^{1}$ Cf. o documentário "O mês que não terminou" (2019), de Francisco Bosco e Raul Mourão, que sintetiza - ao mesmo tempo em que disseca - as imbricações desses eventos políticos no Brasil contemporâneo. O sugestivo título do filme (inspirado em Zuenir Ventura) faz menção às manifestações de junho de 2013 e seus desdobramentos na reeleição e impeachment de Dilma Rousseff, no governo de Michel Temer e na eleição de Bolsonaro - e como tudo isso foi acompanhado por movimentos (de esquerda e direita) nas ruas em todo o país.
} 
eleitorado evangélico - e como o presidente em pleno exercício do mandato vem reagindo ao projeto.

Antes, porém, voltemos a atenção ao ano de 2016, especificamente, à votação pela admissibilidade do impeachment de Dilma Rousseff. Em entrevista concedida à Patricia Fachin (2016) na Revista IHU on-line, Magali Cunha argumenta acerca do pragmatismo evangélico e da superficialidade dos discursos que sustentaram os votos favoráveis ao processo: "eles [os votos] são dedicações 'à família' ou a nomes de pessoas da família, às cidades de vinculação, a Deus, às igrejas a que pertencem, aos cristãos em geral, até mesmo à Nação de Israel (!)". $\mathrm{Na}$ ocasião, foram dois os votos que citaram Israel (a causar o espanto representado pelo ponto de exclamação na resposta da entrevistada): (1) o do deputado Ronaldo Fonseca (então no PROS-DF e, desde 2018, no PODE-DF) - "Sr. Presidente, sem medo de ter esperança e com a convicção de que a Constituição Federal ampara esta sessão; pelo povo brasileiro; pelo Distrito Federal; pela nação evangélica e cristã e pela paz de Jerusalém, eu voto 'sim'. (Palmas.)" (BRASIL, 2016, p. 171-172); e (2) o do deputado Roberto Sales (então no pelo PRB-RJ e, desde 2018, no DEM) - "Sr. Presidente, pela unidade do PRB, pela família e para nenhum governo se levantar contra a Nação de Israel, por São Gonçalo, pelo leste fluminense, pelo Rio de Janeiro, voto 'sim'. (Palmas.)" (BRASIL, 2016, p. 239).

De fato, é urgente compreender, de modo geral, o que evangélicos fundamentalistas e, particularmente, os que são aderentes ao dispensacionalismo pré-milenarista $^{2}$ - associados ao ideário do sionismo cristão 3 - têm a ver com o

\footnotetext{
${ }^{2}$ O dispensacionalismo divide a história em sete eras ou dispensações: (1) da Inocência, (2) da Consciência ou Responsabilidade moral, (3) do Governo humano, (4) da Promessa, (5) da Lei, (6) da Igreja (a atual) e (7) do Reino ou do Milênio (a última, ainda por vir). O prémilenarismo baseado nos pressupostos dispensacionalistas, por sua vez, trata da segunda vinda de Jesus, que vai estabelecer o final dos tempos e o início do reino milenar - com uma importante discussão do lugar da nação de Israel na história da salvação (o que está relacionado com este artigo). Para uma ampliação deste assunto, cf. Campos (2017).

${ }^{3}$ Embora este artigo não seja sobre o sionismo cristão, trata-se de uma categoria relevante para minha reflexão, como se verá mais adiante, ainda que me atenha tão somente à importância que alguns setores evangélicos dão à questão de Jerusalém como capital de Israel. Quanto ao sionismo cristão de modo mais amplo, cf. Wachholz; Reinke (2020), cujo artigo - com desdobramentos atualizados da dissertação de mestrado de André Daniel Reinke (2018), orientada por Wilhelm Wachholz - cumpre o papel de definir sionismo e sionismo cristão, apontar as diferenças entre eles e demonstrar como a questão está presente no Brasil, depois de haver passado pela Grã-Bretanha e EUA - onde deixou suas marcas, não só na religião, mas também na sociedade e na política. De quebra, há uma discussão paralela à deste artigo, relacionando o sionismo cristão e o dispensacionalismo com a política - embora adotem o caminho mais usual de análise no âmbito do Poder Legislativo.
} 
impeachment da presidente Dilma e, segundo o escopo deste artigo, com a eleição de Bolsonaro e a mudança da embaixada brasileira em Israel para Jerusalém.

Como não é possível tratar aqui de toda a história dos milenarismos cristãos, como recorte, proponho um comentário de interesse histórico-teológico para compreensão da contemporaneidade. Para James Barr (1984), John Nelson Darby foi o inventor, no século XIX, do dispensacionalismo (pré-milenarista) na forma como é entendido e aceito até hoje - portanto, estamos diante de um construto recente dentro do cristianismo -, inclusive, em rota de colisão com as interpretações mais tradicionais ou clássicas da teologia. Cyrus Ingerson Scofield e seus seguidores, por sua vez, "se encarregaram da popularização de uma interpretação exclusivista - e um fenômeno tipicamente estadunidense ganhou contornos mundiais (não sem oposição, que fique claro)" (CAMPOS, 2017, p. 55).

\section{Fundamentalistas}

Assumo como hipótese de trabalho que a palavra fundamentalismo e variantes se encontram cada vez mais presentes no debate público e político no Brasil, e também que a proliferação de seu uso não se faz acompanhar, na maioria dos casos, de clareza conceitual - o que vemos, na verdade, é o mesmo nome para muitas coisas. Faço coro com todos os que consideram importante ponderar a respeito da capacidade que o conceito fundamentalismo tem de contribuir para a compreensão da conjuntura nacional, uma vez que o uso e o abuso do termo, por certo, fazem diminuir sua capacidade analítica. Mesmo em face dessa pluralidade de sentidos com a consequente perda da utilização mais rigorosa da palavra, estou com aqueles que defendem a inclusão da categoria fundamentalismo em toda investigação não reducionista do Brasil contemporâneo.

No transcurso do século passado, de fato, o modo de ser fundamentalista e o próprio nome extrapolaram as fronteiras do protestantismo e até mesmo os limites do campo religioso. Portanto, o uso da palavra não está mais limitado aos eventos, lugares e pessoas de sua própria linhagem ou genealogia. Já faz algum tempo que a 
utilização do termo "ultrapassa a especificidade de seus eventos originários" (ALMEIDA; TONIOL, 2018, p. 8). Uma constatação a mais: de epíteto orgulhoso, autoconferido por uma espécie de batismo intramuros, o qualificativo passou a ser quase que exclusivamente categoria de acusação. Não por acaso, os próprios fundamentalistas, nossos contemporâneos, preferem ser chamados por outros nomes.

Posso imaginar que as pessoas possuam alguma noção internalizada do que significa a palavra fundamentalismo, mesmo que não necessariamente associada à teologia protestante. Não obstante, como podem ser muitas as opiniões, registro uma definição de Antônio Flávio Pierucci, a servir de pedra de toque para quaisquer outras:

Fundamentalismo [...] é o nome autoaplicado de uma vertente do movimento protestante conservador, antiliberal, que se formou nos Estados Unidos a partir de 1870 , nas principais denominações protestantes norte-americanas [...]. Seu objetivo básico era defender o princípio da inspiração divina plena da Bíblia, portanto sua inerrância, a autoridade absoluta da letra da Bíblia na vida do cristão. O adversário interno ao campo protestante contra o qual ele se constituiu foram os partidários da teologia liberal e dos métodos da crítica histórica e literária para interpretação da Sagrada Escritura cujo ensino passava a se propagar pelos seminários teológicos e escolas em geral, denominacionais e públicas. $\mathrm{O}$ adversário externo número um era a mentalidade científica moderna, representada emblematicamente pelo darwinismo. (PIERUCCI, 1992, p. 152).

É claro que os debates quanto à utilização mais estrita ou alargada do termo fundamentalismo - que é também um conceito - estão dados no campo científico e são muito importantes. Mas este artigo não é sobre definições do fundamentalismo, portanto, assumo a utilização do conceito de modo ampliado (com os riscos e as críticas que advêm desta opção), por apropriação daquilo que Nancy T. Ammerman (1994) classifica como as características centrais do fundamentalismo consolidado (ou hegemônico) em o Norte da América - e, por extensão, onde quer que sua influência alcance: (1) o evangelismo; (2) a inerrância da Bíblia; (3) o pré-milenarismo; e (4) o separatismo. Na condição de outsiders no assim chamado humanismo secular, o projeto de ingresso na arena público-política 
representou para fundamentalistas a estratégia de conduzir sua pauta religiosa para todas as esferas da sociedade, ou seja, para além da vida de seus fiéis somente (AMMERMAN, 1994).

Então, a fim de delimitar as formas de apreensão de meu objeto de pesquisa, que são as relações entre fundamentalismo (em sentido ampliado) e política no Brasil contemporâneo, adotei a edição digital do jornal Folha de S. Paulo (doravante, Folha) como minha caderneta de campo.4 Por conseguinte, para a construção de dados, em vez de tomar notas dos eventos significativos, minha atitude foi a de buscar e selecionar as notas registradas pelos próprios jornalistas e colunistas da Folha.

Esclareço, ainda, que não é a Folha que está em questão - nem seus textos, nem seus autores -, mas aquilo que aponta como objeto exterior, ou seja, a conjuntura política nacional e o locus ocupado pelo fundamentalismo dentro dela. Assim sendo, não estou interessado na quantidade de vezes em que o jornal aparece aqui, mas, antes, em como ele reverbera o assunto investigado - que é do interesse do grande público, não somente da academia universitária. Com Maria Helena Villas Bôas Concone (1998, p. 131), aprendi que, numa pesquisa qualitativa acerca de um fenômeno (no caso, religioso), os jornais podem nos colocar frente a um tipo bem específico de memória, pois têm a faculdade de nos devolver ao calor da hora: "Sem outros intermediários, por assim dizer, o material fica aqui também, sujeito à busca de sentido e à reorganização, neste caso através da releitura realizada pelo pesquisador. E não é dizer pouco".

Para fazer meus próprios ensaios ou rascunhos - assumo o linguajar de Mills (1972) - dentro dos textos da Folha, que estavam lá, no arquivo digital, sem que eu soubesse de antemão o que encontraria ou o que mais chamaria minha atenção, adotei o procedimento, do modo mais rudimentar possível, de colocar os seguintes descritores, de forma independente (ou seja, um a um), no campo de

\footnotetext{
${ }^{4}$ Disponivel em: https://www.folha.uol.com.br. A escolha da Folha foi presidida pelo acesso integral ao conteúdo do jornal (garantido a assinantes). Fosse outra a fonte de minhas leituras e interpretações, os resultados alcançados poderiam sofrer variações - não substanciais, penso eu, pois os grandes veículos de comunicação cobrem e repercutem os mesmos casos.
} 
buscas do portal do jornal: "fundamentalismo" (singular e plural) e "fundamentalista" (singular e plural). ${ }^{5}$ No período da campanha eleitoral de 2018 , se minhas razões de escolha fossem meramente de ordem quantitativa, por exemplo, a considerar numericamente a presença do fundamentalismo na cobertura das eleições pela Folha, talvez eu devesse tratar do caso em que o candidato Fernando Haddad (PT) classificou a candidatura de Bolsonaro como o casamento do neoliberalismo desalmado (associado a Paulo Guedes) com o fundamentalismo charlatão (ligado a Edir Macedo) - imbróglio que se tornou, inclusive, matéria de decisão judicial.

Entretanto, não foi a direção que segui. Como o objetivo geral deste artigo é relacionar o fundamentalismo (teologia e movimento) com a conjuntura política brasileira, até mesmo em questões de Estado e decisões de governo, de modo interessado, optei pela compreensão das propostas de Bolsonaro quanto ao novo estatuto das relações entre Brasil e Israel, marcadas pela promessa de mudança da embaixada do Brasil em Israel de Tel Aviv para Jerusalém. ${ }^{6}$ Antes, porém, de seguir com a análise pretendida, com a intenção de corroborar a noção já apontada das dificuldades de associação imediata da palavra fundamentalismo com o que ela nomeia -, cito dois de meus curiosos achados na Folha, dentro do recorte temporal referente ao período da campanha eleitoral.

O colunista Luiz Felipe Pondé (16 jul. 2018) relatou o caso de uma amiga (na Europa) indignada com uma nova forma de ativismo radical na França: "Não se trata de fundamentalismo islâmico matando ocidentais sujos, mas sim de fundamentalistas veganos ameaçando açougueiros franceses". Dois comentários: (1) parece fazer sentido aos leitores da coluna, sem muitas mediações, a expressão "fundamentalistas veganos"; (2) pela estrutura do texto, Pondé nos leva a considerar que a primeira aproximação possível de um ativismo radical - na

\footnotetext{
${ }^{5}$ Conforme as ferramentas disponíveis no site da Folha, num primeiro movimento, fiz a varredura no período personalizado de 10 de julho de 2018 a 31 de dezembro de 2018, a fim de avaliar a presença dos descritores - e suas consequências - no período de campanha eleitoral à presidência. Descontados alguns resultados duplicados e repetidos, listei cerca de seis dezenas de textos diferentes em que os quatro descritores aparecem - e não tenho como tratar de todos.

${ }^{6}$ Uma vez estabelecida a temática, num segundo movimento, em vez de a apresentação dos textos ser definida pela cronologia, ou seja, pela sequência das datas em que aparecem no jornal, decidi-me pelo critério de conferir certa organização didática (e arbitrária) aos que tratam de meu recorte.
} 
França, pelo menos -, alçada pela memória individual ou imaginário coletivo, deve ser com fundamentalistas islâmicos. De todo modo, ambos os usos estão longe de uma identidade protestante ou evangélica relacionada ao conceito fundamentalismo. Além disso, parece fazer muito sentido (sempre) a máxima de que fundamentalistas são os outros.

João Pereira Coutinho (4 set. 2018), por sua vez, escreveu sobre religião, ciência e ateísmo, e emitiu a seguinte opinião: "Ironicamente, o primeiro pecado dos novos ateístas" - refere-se ele a Sam Harris, Richard Dawkins, Christopher Hitchens - "é serem tão fundamentalistas como os mais acérrimos fundamentalistas". Meu comentário: no reino do dever ser, espera-se que ateístas (cientistas, filósofos etc.) sejam uma espécie de reserva cultural contra os fundamentalismos vários. No mundo como ele é, entretanto, ateístas (cientistas, filósofos etc.) podem ser tão fundamentalistas como os terroristas islâmicos do 11 de setembro ou aqueles que leem de forma literal o livro de Gênesis (para ficar somente com dois dos exemplos mencionados pelo próprio colunista do jornal).

Então, pergunto: quem são os mais acérrimos fundamentalistas? Dentre as muitas possibilidades, no Brasil contemporâneo, parece-me impossível não pensarmos que a mais espontânea das respostas seja a seguinte: os evangélicos. Vamos, então, a eles (os evangélicos), cuja posição é o que me interessa na relação proposta entre fundamentalismo e política, particularmente ambientada na campanha eleitoral à presidência da República em 2018, mas não somente no período correspondente a ela - ou seja, também no exercício do mandato presidencial de Bolsonaro.7

\section{Evangélicos fundamentalistas}

Entendo ser tarefa metodológica decisiva de toda pesquisa bibliográficodocumental, como a que embasa este artigo, definir quais são as contribuições para

\footnotetext{
${ }^{7}$ Quanto à leitura da Folha e seleção dos textos para esta análise conjuntural, meu terceiro movimento foi o de buscar, como garimpeiro, as repercussões do assunto - mudança da embaixada do Brasil em Israel para Jerusalém - no primeiro ano de mandato do presidente Bolsonaro, ou seja, não mais pela utilização dos descritores "fundamentalismo(s)" e "fundamentalista(s)".
} 
o campo acadêmico: "Ao trabalharem com literaturas os pesquisadores podem denominar a(s) conversa(s) em que se envolverão e articular o 'naco' de conhecimento que estão oferecendo à comunidade de estudo" (KAMLER; THOMSON, 2015, p. 45-46). As conversas que entabulei com os referenciais teóricos e as fontes ficarão claras no encadeamento dos arrazoados, portanto, restame explicitar o "naco" de conhecimento que entrego aos estudos das imbricações entre fundamentalismo e política no Brasil contemporâneo.

Para justificar como o objeto de minha investigação cumpre o papel de aglutinar interesses da academia universitária e da sociedade brasileira, tomo emprestada a chamada de capa da Revista Pesquisa FAPESP (edição de dezembro de 2019): "Fenômeno evangélico - Em 10 anos, adeptos crescem 61\% no Brasil e chegam a diferentes esferas de participação, como o Congresso". Além do texto, a ilustração (elemento visual) da capa é também bastante sugestiva ao destacar a mão de uma pessoa que segura uma Bíblia aberta. Suponho que nenhuma outra imagem esteja tão imediatamente ligada a evangélicos no Brasil como a de um sujeito que discursa com um exemplar das Escrituras na mão (para legitimar seus argumentos), do pregador que grita na praça pública ao apresentador de fala mansa e pausada dos programas religiosos de televisão.

Quanto à novidade que posso acrescentar ao caso, destaco uma primeira ponderação: embora a Revista Pesquisa FAPESP trate de evangélicos, não de fundamentalistas, de minha parte, estou a fazer a passagem de evangélico a evangélico fundamentalista, com o objetivo de extrair uma compreensão possível que decorre justamente do acréscimo do qualificativo fundamentalista ao nome evangélico. Isto é, a conjunção (evangélicos fundamentalistas) particulariza os fundamentalistas dentro do campo geral dos evangélicos. Interessa-me não deixar cair no esquecimento que a especificidade fundamentalista dos evangélicos ainda guarda uma relação - que até pode ter sido mais direta antigamente, mas que não deixou de existir até hoje - com a leitura literal do texto bíblico. 
Devo reconhecer que a ação fundamentalista mais notável no Brasil contemporâneo se encontra associada à passagem da religião à esfera pública (a incluir a ação política), como radicalização de seu traço separatista (não como negação dele), haja vista o caráter proselitista do fundamentalismo. Assim, considero, de fato, que a chegada de evangélicos à política, notadamente pelas vias do Poder Legislativo, talvez seja a face mais visível de um crescimento do fundamentalismo no Brasil - o que não é pouca coisa, mas não a única. Assim, estou habilitado a apresentar a segunda ponderação quanto à novidade que pretendo acrescentar: embora concorde com a noção de que a chegada dos evangélicos à política se dê muito mais pelos caminhos do Poder Legislativo, neste artigo, procuro destacar os mecanismos de relação de evangélicos fundamentalistas com o campo próprio do Poder Executivo.

Por fim, uma terceira ponderação - que exige um desdobramento mais longo do que as anteriores- ligada ao fato de eu propor o debate neste artigo dentro dos limites teórico-metodológicos das Ciências da Religião e Teologia. Voltemos ao periódico da FAPESP:

Nos últimos 30 anos, os evangélicos aumentaram sua participação na vida pública transcendendo a fronteira da Igreja para ocupar espaços na mídia, na cultura e na política. Inicialmente objeto de estudos na sociologia brasileira, o fenômeno passou a chamar a atenção de pesquisadores de outras áreas do conhecimento, como a antropologia, após a divulgação dos resultados do último Censo, realizado pelo Instituto de Geografia e Estatística (IBGE) em 2010, que identificou aumento de 61\% na população evangélica do país, no período de 10 anos (QUEIROZ, 2019, p. 12).

Mais interessante do que os números - afinal, tratar dos resultados do último Censo parece temerário, afinal, já faz muito tempo que ele aconteceu, e estamos às vésperas de outro recenseamento nacional -, destaco as mencionadas áreas do conhecimento afeitas à pesquisa do fenômeno evangélico e sua penetração formal na política brasileira: de partida, a Sociologia, posteriormente, seguida pela Antropologia. Quero, assim, retornar à parte que me cabe nos estudos da presença evangélica que, por extrapolação de fronteiras eclesiásticas e denominacionais, alcança a cena público-política no Brasil, para afirmar meu intento de avaliar - de 
um ponto de vista das Ciências da Religião e Teologia - como a aproximação da categoria fundamentalismo com a de evangélico (que, no Brasil, nomeia protestantes históricos ou tradicionais, pentecostais e neopentecostais) ${ }^{8}$ contribui para uma análise conjuntural da política brasileira.

Devemos considerar o fundamentalismo, antes de tudo, como uma categoria teológica, com inequívocas consequências sociais e políticas, portanto, assim como a reportagem de Queiroz (2019) evidencia que a presença ampliada de evangélicos na política brasileira já é um objeto de investigação consagrado na Sociologia - e, mais recentemente, vem chamando a atenção da Antropologia também -, quero asseverar, mesmo que para isso tenha de disputar espaço com outras ciências, que o objeto é aderente também à área das Ciências da Religião e Teologia e sua árvore do conhecimento, ainda que cientistas da religião e teólogos talvez tenham saído com alguma atraso no processo de investigação do Brasil contemporâneo no que se refere às afinidades entre evangélicos e política.

Julgo pertinente registrar um exemplo a mais de como as relações entre evangélicos fundamentalistas e política são, atualmente, de interesse tanto da academia universitária como do conjunto da sociedade brasileira. Também no mês de dezembro de 2019, a Revista Cult publicou o dossiê "Fé e política", com o seguinte texto de capa: "Teólogos refletem sobre movimentos progressistas e conservadores no cristianismo". No artigo "A hegemonia pentecostal no Brasil", constata Magali Cunha:

Bispo Edir Macedo, missionário R. R. Soares, apóstolo Estevam Hernandes, pastor Silas Malafaia, bispo Valdemiro Santiago, pastora Damares Alves, apóstolo Rina, pastor Marco Feliciano, apóstola Valnice Milhomens, pastora Cassiane. O que essas lideranças religiosas, destacadas por mídias brasileiras, têm em comum? São pentecostais, o segmento religioso cristão que mais se expandiu, numérica e geograficamente, no Brasil nas últimas décadas. Hoje, compreender o pentecostalismo é imprescindível para quem se interessa pelas dinâmicas socioculturais e políticas que envolvem o país. (CUNHA, 2019, p. 24).

\footnotetext{
${ }^{8}$ No Brasil contemporâneo, o conhecimento do senso comum, não isento apesar da espontaneidade, considera que fundamentalista é o evangélico, e evangélico, por sua vez, é o pentecostal - opiniões que não levam em conta, por exemplo, toda a história original dos protestantes históricos como os fundadores do fundamentalismo. $\mathrm{O}$ escopo deste texto não contempla a discussão dessas categorias, nem propõe um sistema de classificação em que elas se encaixem, por conseguinte, não considero demasiado registrar, ainda que de passagem, que nem todo evangélico é pentecostal e que nem todo evangélico (pentecostal ou não) é fundamentalista.
} 
Acrescentar o fundamentalismo como categoria analítica à dinâmica apontada por Cunha (2019) - das relações de evangélicos com a política no Brasil é uma contribuição, como já apontei, que meu artigo pretende oferecer à área dos estudos da religião no Brasil, pela passagem do tema de um campo mais estrito das Ciências Sociais para outro em que as Ciências da Religião e a Teologia estejam incorporadas, com as competências e especificidades que atribuem à investigação do tema. A meu ver, a persecução desse propósito deve levar em conta, ao menos, duas dimensões, sendo que a primeira vem de uma observação de Antonio Gouvêa Mendonça quanto à diferença entre sectarismo e fundamentalismo, e o lugar do neopentecostalismo na discussão:

Ora, boa parte das seitas, regra geral como são chamados os grupos neopentecostais, não são fundamentalistas, embora intolerantes, porque sua intolerância não parte da forma de leitura da Bíblia, embora quase sempre literal, reconheça-se, mas de outros pontos de disputa de mercado religioso. Em suma, nesses grupos a Bíblia não tem lugar de destaque e, por esse fato, não podem ser classificados como fundamentalistas no sentido rigoroso do conceito. (MENDONÇA, 2002, p. 29).

Feita a ressalva do cuidado necessário quanto à associação direta do neopentecostalismo com o fundamentalismo - é bom ressaltar que Mendonça (2002) não abre mão de considerar que também os neopentecostais leem a Bíblia literalmente (quase sempre) -, a segunda dimensão a ser levada em conta é aquela que vai permitir, pelo esgarçamento de sentido da categoria, considerar fundamentalismo como a passagem dos evangélicos ao ato político. Para corroborar a ideia, valho-me do seguinte argumento de Karen Armstrong acerca de um período (1974-1979) que ela mesma classifica como "a ofensiva" fundamentalista nos EUA:

$\mathrm{O}$ ataque fundamentalista surpreendeu muitos secularistas. Eles achavam que a religião nunca voltaria a desempenhar um papel importante na política, porém ao terminar a década de 1970 houve uma explosão de fé militante. [...] Nos Estados Unidos Jerry Falwell fundou, em 1979, a Maioria Moral, instigando os fundamentalistas protestantes a envolver-se na política e a contestar a legislação estadual e federal que impunha uma agenda "humanista secular". (ARMSTRONG, 2001, p. 312). 
Ela explica também que por décadas os fundamentalistas estadunidenses se valeram da sólida democracia em seu país para livre expressão de suas convicções, bem como para utilização das instituições democráticas a serviço de seus interesses. "Entretanto, ao encerrar-se a década de 1970, começaram a pensar que, ao invés de afastar-se da sociedade, como vinham fazendo por cerca de cinquenta anos, deviam engajar-se na política" (ARMSTRONG, 2001, p. 345). A ideia era a recondução da nação aos caminhos do bem, com uma clara pauta de costumes, a fim assegurar ao eleitorado evangélico a ocupação de espaços na esfera pública. Dos EUA, o modelo foi exportado, com maior ou menor força, mais ou menos rapidamente, para todo o continente americano.

O que estou chamando de passagem ao ato público-político por evangélicos fundamentalistas pode ser levada a efeito pelo neopentecostal, pentecostal ou protestante tradicional, desde que presidida no que concerne à temática deste artigo pela leitura literal do texto bíblico, mais particularmente ainda, pela relação de setores dentre os evangélicos fundamentalistas com teologia a respeito da cidade de Jerusalém. Porque eles "não leem a Bíblia simplesmente para aprender história ou princípios morais. Eles esperam também encontrar nas Escrituras pistas sobre o futuro destino deste mundo, o que acontecerá no final dos tempos" (AMMERMAN, 1994, p. 6; tradução nossa).

Para sintetizar conceitos que utilizei até este ponto, cito Robert O. Smith (p. 29-30, 2010), para quem há uma relação do sionismo cristão com formas politicamente mobilizadas do fundamentalismo cristão (caracterizado pelo estrito literalismo na interpretação de profecias bíblicas): "Para compreender o sionismo cristão, deve-se começar com seu sistema teológico básico: o dispensacionalismo pré-milenarista" (tradução minha), cuja origem ele atribui Darby e a popularização a Scofield. Ainda assim, reconhece também a existência de outras formas de organização e manifestação do sionismo cristão, para além do modelo dispensacionalista (mas que não entram na minha discussão). 


\section{Evangélicos fundamentalistas sionistas}

Como o lugar da Folha neste artigo já foi explicado, passo imediatamente a meu próprio exercício de compreensão do objeto - que são as imbricações do assim chamado sionismo cristão com a eleição de Bolsonaro, e como isso coloca em questão a democracia brasileira ${ }^{9}$ - por uma coluna de André Singer ( 8 dez. 2018) sobre a dificuldade de emitir predições concernentes ao mandato do presidente eleito, justamente por esbarrar na imprevisibilidade programada do próprio Bolsonaro. É bem verdade que o cenário de imprevisibilidade já estava instaurado na conjuntura política brasileira, pelo menos desde 2013. ${ }^{10}$

De todo modo, logo no início dos argumentos, Singer (8 dez. 2018) pergunta: "Mudança da embaixada brasileira em Israel para Jerusalém? Ninguém informa quando ocorrerá, o que na prática significa suspender o projeto, sem descartá-lo". Quase às vésperas da posse do presidente eleito, a tese do colunista era bastante clara (e plausível): se, durante a campanha eleitoral, a plataforma de Bolsonaro pôde ser vaga e contraditória - por exemplo, "fundamentalista" e "modernizante" ao mesmo tempo, para usar palavras do próprio Singer (8 dez. 2018) -, no exercício do mandato, o presidente seria obrigado a tomar decisões (inclusive, mas não somente, sobre a localização da embaixada do Brasil em Israel).

À vista disso, por que mudar a embaixada do Brasil em Israel de Tel Aviv para Jerusalém? Anna Virginia Balloussier (7 nov. 2018) já havia dado resposta satisfatória à questão, com base no pressuposto analítico do peso do voto evangélico no Brasil de 2018 como um componente eleitoral similar a eventos ocorridos nos EUA em 2016 (o que, por comparação, aproximaria Bolsonaro de Donald Trump). Mas, afinal, qual é a relação de evangélicos brasileiros (que me interessam mais, ainda que não possa prescindir de olhar para os estadunidenses)

\footnotetext{
${ }^{9}$ Por óbvio, o que coloca a democracia em questão não é a crença dos sionistas cristãos - que é de responsabilidade deles mesmos, individualmente ou em grupo, na esfera da vida privada ou em comunidade religiosa -, mas o problema passa a existir quando são tomadas decisões de Estado e ações de governo (em qualquer um dos três poderes) para atender à pressão de tal grupo religioso e de suas especificidades teológicas.

10 “Entre 2013 e 2018, foram frequentes os momentos nos quais acadêmicos, políticos, burocratas estatais, jornalistas, militantes, entre outros, pouco ousaram traçar cenários, mesmo os de curta duração, tal o grau de instabilidade política, em período eleitoral ou fora dele" (ALMEIDA, 2019, p. 191).
} 
com Israel? E mais: como o qualificativo fundamentalista (com todos aqueles outros recortes definidos anteriormente) associado ao nome evangélico ajuda a compreender o caso? Porque bastante previsíveis as perguntas, a própria jornalista convidou Valdinei Ferreira (pastor da Primeira IPI de São Paulo e doutor em Sociologia pela USP) para explicar que a mudança do olhar dos evangélicos para Jerusalém - do desinteresse à importância decisiva ${ }^{11}$ - veio com "o advento da 'teologia fundamentalista norte-americana, desenvolvida a partir dos anos 1930, que passou a interpretar de modo literal profecias de uma futura restauração de Jerusalém"' (BALLOUSSIER, 7 nov. 2018).

Faço notar, portanto, que essa ideia fixa em torno de Israel não é característica de evangélicos em geral, mas de certos grupos que estou chamando de fundamentalistas. Por quê? Ainda segundo Ferreira, na matéria de Balloussier (7 nov. 2018), esse modo de interpretação ganhou maior consistência depois da criação do Estado de Israel em 1948, principalmente no imaginário de pentecostais e neopentecostais, por serem muito apegados a alguns textos proféticos do Primeiro Testamento e do Apocalipse cristão. Enfim, são evangélicos que veem nos acontecimentos relativos a Israel o cumprimento necessário de algumas das profecias que, segundo sua própria teologia da história, devem anteceder a volta de Cristo (segundo advento ou segunda vinda) e o fim dos tempos. Há uma clara associação entre Israel (o do passado bíblico, portanto, uma categoria teológica) com Israel (o Estado contemporâneo).

Porque a discussão é complexa, cito os apontamentos do sociólogo Paul Freston, entrevistado como fonte pela jornalista Daniela Kresch (25 jan. 2020) em matéria sobre cristãos sionistas para a Folha: (1) é inusitada a aproximação de cristãos (sionistas) sul-americanos com Israel, pois os países da região historicamente não guardam uma postura pró-Israel, de sorte que o movimento "se tornou uma fonte de soft power importante para o país"; (2) o sionismo cristão existe desde o século XVI, sendo anterior ao judaico, que é do XIX, portanto, deve

\footnotetext{
${ }^{11}$ Segundo Ferreira, "durante muitos séculos, os protestantes não se importaram muito com Jerusalém. Sob o domínio dos britânicos, o interesse ainda era insignificante. Jerusalém sempre teve mais importância simbólica para judeus, católicos e muçulmanos" (BALLOUSSIER, 7 nov. 2018).
} 
ser superada a tentação de o considerar fenômeno recente e estadunidense (importado pelo Brasil, por exemplo); (3) em 1659, o padre Antônio Vieira já profetizava o retorno dos judeus à Palestina, com a reconstrução do templo em Jerusalém, assim, teria sido ele "o primeiro cristão sionistas do Hemisfério Sul"; (4) depois da organização do Estado de Israel, em 1848, surgiram formas mais modernas de sionismo cristão - por certo, é neste ponto que se localiza o cerne da opinião de Valdinei Ferreira -, os evangélicos começam a ganhar destaque a partir dos anos 1960 e "a ascensão de neopentecostais é ainda mais recente". ${ }^{12}$

Em artigo publicado na Revista IHU On-line, no calor dos acontecimentos, Carlos Caldas (2019) ofereceu uma explicação teológica e política para o interesse de setores evangélicos brasileiros que abraçam o dispensacionalismo prémilenarista sionista (porque, vale lembrar, nem todo sionismo cristão é necessariamente dispensacionalista) no reconhecimento de Jerusalém como capital única de Israel, com o consequente reconhecimento da soberania do Estado de Israel sobre toda a cidade de Jerusalém - da qual, destaco o seguinte trecho:

[...] a partir de uma interpretação literalista de Apocalipse 2o, os dispensacionalistas creem que Jesus Cristo descerá dos céus, e reinará sobre todo o mundo a partir de Jerusalém durante mil anos de trezentos e sessenta e cinco dias de vinte e quatro horas cada. Durante estes mil anos Satanás estará preso, e depois será solto, liderando uma grande batalha contra os servos do Senhor no vale do Armagedom, em Israel. Satanás e suas hostes serão derrotados definitivamente, e haverá a paz eterna para os salvos, e o castigo eterno para os condenados (CALDAS, 2019).

Interessante notar que a mesma Revista IHU On-line havia publicado um artigo de Jonathan Merritt (2017) ${ }^{13}$ a tratar de questões paralelas às de Caldas, mas, no caso, relacionadas somente a Trump e a evangélicos estadunidenses. Em sua abordagem, Merritt preenche uma lacuna que está aberta até aqui, a saber, para os evangélicos dispensacionalistas sionistas, seguidores de uma hermenêutica literalista do texto bíblico (a caracterizar seu fundamentalismo), "quando os

\footnotetext{
12 De outro modo, Smith (p. 29, 2010) corrobora as informações de Freston: "é importante apontar que William E. Blackstone [um sionista cristão] apresentou ao Presidente Harrison a recomendação 'em favor da restauração da Palestina aos judeus' em 1891, enquanto o panfleto Der Judenstaat de Theodor Herzl não foi publicado senão em 1896" (tradução minha).

${ }^{13}$ Publicado originalmente em America: The Jesuit Review, em 11 de dezembro de 2017, com o seguinte título: "Understanding the Evangelical Obsession with Israel". Disponível em: https://www.americamagazine.org/politics-society/2017/12/11/understandingevangelical-obsession-israel. Acesso em: 24 jun. 2020.
} 
últimos dias chegarem, Deus trará o povo judeu de volta a Israel, onde reconstruirão o templo e, finalmente, aceitarão Jesus como o Messias legítimo. Isso desencadeará o retorno de Jesus e seu reinado".

Não é tarefa fácil determinar quantos cristãos aceitam o dispensacionalismo como visão de mundo - tanto nos EUA, segundo Merritt (2017), quanto no Brasil, como eu suspeito -, até porque, mesmo dentre as pessoas que seguem tacitamente seu ideário, nem todas sabem exatamente o que é o dispensacionalismo ou conhecem suas variantes. Ainda assim, o articulista oferece números (para o caso dos EUA) que lançam luz à questão:

Uma enquete de 2015 informou que 60\% dos evangélicos dizem que a nação [moderna] de Israel foi estabelecida como resultado da profecia bíblica. $70 \%$ dizem que "Deus tem um relacionamento especial com a nação moderna de Israel", e $73 \%$ acreditam que "os acontecimentos em Israel são parte das profecias no Livro do Apocalipse". Assim, para muitos evangélicos, a decisão de Trump de mudar a embaixada americana para Jerusalém tratava-se muito mais do que de geopolítica (MERRITT, 2017).14

Resta, enfim, entender a entrada de Bolsonaro nessa história. De forma instigante, Igor Gielow (29 out. 2018) analisa a primeira live de Jair Bolsonaro após a confirmação de seu triunfo no segundo turno, destacando os quatro livros sobre a mesa do candidato eleito, como uma espécie de recado tanto a seguidores como a seus críticos, passando pelos assustados e desconfiados: a Constituição de 1988 (para se apresentar como democrático), as memórias de Winston Churchill (estadista), um livro de Olavo de Carvalho (conservador) e uma Bíblia (cristão), na verdade, um exemplar da Bíblia A mensagem (de Eugene Peterson), muito popular no meio evangélico brasileiro.

Católico, ele [Bolsonaro] foi batizado evangélico em Israel em 2016 pelo então pré-candidato a presidente Pastor Everaldo.Sua defesa de Israel em detrimento da Palestina na política externa decorre dessa proximidade.

\footnotetext{
${ }^{14}$ Em contrapartida, Merritt (2017) também apresenta constatações noutras direções sobre o mesmo assunto nos EUA: "Com certeza, nem todos os cristãos evangélicos mantêm essas crenças sobre Israel e os tempos finais. Alguns rejeitam a noção de que as promessas de mais de 4.000 anos, feitas por Deus a Abraão, se aplicariam à moderna [nação de] Israel". Além disso, evoca números de que os efeitos da teologia dispensacionalista vem diminuindo dentre os mais jovens: "os evangélicos americanos com menos de 35 anos são significativamente menos propensos a ter uma visão positiva da nação de Israel do que os mais antigos, assim como $66 \%$ desses mesmos evangélicos acreditam que 'os cristãos devem fazer mais para amar e cuidar do povo palestino'".
} 
Para os evangélicos, particularmente os neopentecostais, é uma questão de restaurar a "verdade bíblica" ter o Estado judeu estabelecido na região. Vertentes mais fundamentalistas inclusive alegam que isso é precondição para a volta de Jesus Cristo à Terra. (GIELOW, 29 out. 2018).

Às vésperas do final de 2018, o mesmo Gielow escreveu dois textos a respeito da visita de Binyamin Netanyahu, primeiro-ministro do Estado Israel, à posse de Bolsonaro, nos quais o fundamentalismo aparece associado a evangélicos: "Netanyahu terá encontro com Bolsonaro no Brasil antes da posse" (GIELOW, 18 dez. 2018) e "Premiê de Israel não deve mais ir à posse de Bolsonaro" (GIELOW, 25 dez. 2018). ${ }^{15}$ Em suma, o jornalista trata da anunciada guinada brasileira em favor de Israel no caso dos conflitos com a Palestina e outros países árabes no Oriente Médio, e da promessa de mudança da embaixada brasileira em Israel para Jerusalém (mesmo contra recomendação do Conselho de Segurança da ONU). Gielow destaca, ainda, a influência de evangélicos brasileiros (parte da base eleitoral de Bolsonaro) na motivação para essas transformações, uma vez que, por imitação de seus congêneres estadunidenses, acreditam nossos evangélicos fundamentalistas que o estabelecimento definitivo de Israel e de sua capital em Jerusalém sejam condições necessárias para o retorno de Cristo.

Cabe uma digressão para mostrar o outro lado, ou seja, qual o posicionamento de Israel em relação aos evangélicos no mundo. Em 2020, o descritor "sionismo cristão" apareceu na já citada matéria de Daniela Kresch na Folha, cujo objetivo principal foi demonstrar que, para Israel, hoje, não há apoio mais importante do que o dos evangélicos espalhados pelo mundo. O Brasil, por exemplo, é tido pela reportagem como um dos mais significativos exemplos de aliança entre cristãos sionistas e judeus conservadores; para o historiador Leonel Karaciki, citado pela jornalista, o próprio governo de Netanyahu "passou a dar atenção a cristãos pró-Israel, como evangélicos pentecostais no Brasil e na África, e a deixar em segundo plano judeus da diáspora que criticam o país" (KRESCH, 25 jan. 2020).

\footnotetext{
${ }^{15}$ No final das contas, embora a situação política não fosse tranquila em Israel, em virtude de crises profundas na coalizão conservadora que o sustenta e de críticas e denúncias de seus adversários, Netanyahu ficou no Brasil e participou da posse do presidente Bolsonaro.
} 
Voltando aos textos de Gielow, há outra questão dentro da temática que não pode passar despercebida: o mero anúncio da decisão política de mudança da embaixada - por motivação religiosa, a saber, por pressão de setores evangélicos fundamentalistas - criou um problema adicional para o Brasil: "é que boa parte de sua produção de carne de frango e bovinos é feita sob as especificações islâmicas, o chamado halal", desse modo, "há o temor na agroindústria nacional que um apoio explícito a Israel feche mercados, hoje responsáveis por quase metade das exportações desses itens" (GIELOW, 18 dez. 2018).

Balloussier já havia mostrado os contornos, também econômicos, do impasse em que Bolsonaro se deixava enredar (quanto ao caso da embaixada, quero deixar claro, pois é somente dele que estou tratando aqui):

A retaliação começou pelo Egito, que cancelou uma missão oficial brasileira, ato um tanto incomum no protocolo da diplomacia, após as declarações de Bolsonaro. Os países árabes são o segundo maior comprador de proteína animal brasileira, e um boicote do grupo será indigesto para outra bancada próxima a Bolsonaro. Na chamada frente BBB (Boi, Bíblia e Bala) do Congresso Nacional, os ruralistas podem levar a melhor sobre os colegas evangélicos. (BALLOUSSIER, 7 nov. 2018).

Nos EUA, Trump também prometera em campanha mudar a embaixada de seu país em Israel de Tel Aviv para Jerusalém, a fim de agradar o eleitorado evangélico. Assumiu o mandato presidencial e cumpriu a promessa - depois de um tempo, é verdade, mais precisamente, em maio de 2018 -, a despeito de alguns conselheiros e outros tantos líderes internacionais considerarem imprudente sua atitude. "Mas Trump, bom, Trump é Trump. Líder da maior potência mundial, ele deu de ombros e foi adiante com a promessa eleitoral" (BALLOUSSIER, 7 nov. 2018).

De quebra, Bolsonaro é Bolsonaro:

[...] ao contrário do americano que tanto o inspira, o presidente eleito do Brasil pode não ter tanta musculatura política para queimar. Ele garantiu, logo depois de eleito, que faria de Jerusalém a sede da diplomacia verdeamarela, mas nesta semana voltou atrás e disse que a mudança "não está decidida" (BALLOUSSIER, 7 nov. 2018). 
Igor Gielow trata das resistências enfrentadas por Bolsonaro em torno da difícil tarefa de cumprir sua promessa de campanha, como consequência de o mercado ser insaciável e se impor na tomada de decisões políticas:

O problema está na natureza terrena das coisas. Assim que a ideia foi ventilada [por Bolsonaro], produtores de carne brasileiros foram ao então governo Michel Temer levar a preocupação da categoria. O Brasil é um dos maiores exportadores de proteína animal halal, feita sob princípios de produção e abate islâmicos, e poderia perder mercados com uma atitude francamente pró-Israel. (GIELOW, 28 mar. 2019).

Também são insaciáveis os evangélicos fundamentalistas em sua sanha de conquistar o mundo. Ainda que, por enquanto, estejamos assistindo à vitória da carne sobre o espírito.

\section{Conclusão}

No exercício do Poder Executivo, Bolsonaro acusou o golpe - no sentido do boxe, não no da política - que André Singer (8 dez. 2018) anunciara, ou seja, uma coisa é a campanha e outra é o mandato. A solução, pelo menos, temporária e paliativa, para a questão da transferência da embaixada foi a abertura de um escritório de representação comercial brasileiro em Jerusalém. Decisão que foi considerada uma unanimidade, por desagradar à totalidade das forças envolvidas no caso, com destaque para os evangélicos, segundo o escopo deste artigo, mas sem desprezar a insatisfação de israelenses (que queriam mais) e palestinos (que queriam menos).

No mesmo dia do anúncio do escritório comercial em Israel pelo governo federal, o deputado e pastor Marco Feliciano (então no PODE-SP e hoje no REPUBLICANOS-SP) fez questão de lembrar ao presidente que o segmento evangélico, "um terço do eleitorado brasileiro, que deu uma vantagem de 11 milhões de votos ao presidente Jair Bolsonaro, garantindo sua eleição, confia que ele cumprirá sua palavra e em breve mudará a embaixada brasileira para Jerusalém" (EVANGÉLICOS..., $1^{\circ}$ abr. 2019). 
A mesma reportagem considera que o sentimento de parte considerável dos evangélicos fundamentalistas no Brasil era o de estelionato eleitoral (expressão muito cara à oposição ao petismo, particularmente quanto aos eventos ligados ao impeachment da presidente, obviamente, por outras razões). "Outros evangélicos, contudo, pedem calma, dizem que 'o tempo é de Deus' e já, já Bolsonaro cumpre a palavra" (EVANGÉLICOS..., $1^{\circ}$ abr. 2019). Dentre eles, Silas Malafaia, que fez lembrar a todos o fato de Trump haver levado certo tempo até cumprir a promessa de mudar a embaixada dos EUA para Jerusalém:

"Bolsonaro disse para mim que a mudança seria paulatina", afirmou o pastor [Malafaia] à reportagem. "Ele já disse que o casamento está marcado. Os americanos, um monstro de potência, levaram nove meses. Por que um governo que não tem nem cem dias vai fazer?" (EVANGÉLICOS..., 1 abr. 2019).

Quanto às críticas a Bolsonaro, em 15 dezembro de 2019 (dia da inauguração do escritório comercial do Brasil em Jerusalém), o próprio primeiro-ministro israelense cobrou a promessa de mudança da embaixada brasileira para Jerusalém, colocando 2020 como meta a ser cumprida - e quem garantiu a ele tratar-se de um compromisso de Jair Bolsonaro foi o filho do presidente e deputado federal Eduardo Bolsonaro (PSL-SP) (NETANYAHU..., 15 dez. 2019). Mas a mudança parece ter ficado mesmo para 2021, com garantia dada por Bolsonaro a Malafaia (espécie de porta-voz da presidência para um segmento específico dos evangélicos no Brasil):

"Estamos caminhando para isso. Não vou dizer 20, no máximo 21, se Deus quiser, vai nascer sem atritos", afirmou o presidente durante uma conversa com o pastor Silas Malafaia gravada em dezembro do ano passado [2019] e veiculada nesta segunda-feira (3) no canal do YouTube do líder religioso. (FERNANDES, 3 fev. 2020).

Por fim, recorro a um último texto da Folha, ${ }^{16}$ do colunista Gregorio Duvivier (7 ago. 2019), que, com sua verve peculiar, deixa-nos a seguinte

\footnotetext{
${ }^{16}$ Reconhecendo, com certo lamento, que tantos outros tiveram de ficar de fora, mas, como afirmei na introdução, a pesquisa continua, pois é neste projeto que estou envolvido.
} 
provocação: "Tenho tido saudade de quando o apocalipse era um capítulo delirante da Bíblia e não um programa de governo. Tenho tido saudade de quando Armaggedon era só um filme ruim". Nos momentos em que certa teologia (escatologia) - de corte dispensacionalista pré-milenarista sionista, portanto, fundamentalista, segundo meus argumentos neste artigo - ultrapassa as fronteiras da esfera religiosa e influencia questões de Estado e ações de governo, devemos ficar atentos ao que já está aí, bem como ao que mais pode vir pela frente notadamente quanto ao estatuto da democracia no Brasil estar colocado em questão.

No arremate de sua coluna de opinião e humor, Duvivier (7 ago. 2019) desenha com palavras uma imagem do paraíso como um lugar de liberdade para reclamarmos de tudo o que nos incomoda: "Ah, que saudade de reclamar da tomada de três pinos", exemplifica. Ele trata, portanto, de coisas terrenas. Mas, para alguns evangélicos fundamentalistas, o paraíso é uma cidade no porvir, que pode ser chamada por muitos nomes - inclusive, Nova Jerusalém (a simbologia é muito forte) -, na qual as ruas são de ouro e de cristal. Corolário: nada a estranhar se, desde já, as florestas derem lugar aos garimpos, às monoculturas e seus agrotóxicos e, principalmente, à boiada (que está a pedir passagem).

\section{REFERÊNCIAS}

ALMEIDA, Ronaldo de. Bolsonaro presidente: conservadorismo, evangelismo e a crise política. Novos Estudos Cebrap, São Paulo, v. 38, n. 1, p. 185-213, jan.-abr. 2019. Disponível em: http://www.scielo.br/pdf/nec/v38n1/1980-5403-nec-38-01-185.pdf. Acesso em: 26 ago. 2019.

ALMEIDA, Ronaldo de; TONIOL, Rodrigo. Introdução. In: ALMEIDA, Ronaldo de; TONIOL, Rodrigo (org.). Conservadorismos, fascismos e fundamentalismos: análises conjunturais. Campinas: Editora da Unicamp, 2018. p. 7-13.

AMMERMAN, Nancy T. North American Protestant fundamentalism. In: MARTY, Martin E; APPLEBY, R. Scott. Fundamentalism observed. Chicago: The University of Chicago Press, 1994. p. 1-65.

ARMSTRONG, Karen. Em nome de Deus: o fundamentalismo no judaísmo, no cristianismo e no islamismo. São Paulo: Companhia das Letras, 2001. 
BALLOUSSIER, Anna Virginia. Relação de Bolsonaro e Trump com Jerusalém passa por apoio evangélico: o Brasil de 2018 tem um componente similar aos EUA de 2016: o peso do voto do segmento. Folha de S. Paulo, São Paulo, 7 nov. 2018. Disponível em: https://www1.folha.uol.com.br/poder/2018/11/relacao-de-bolsonaro-e-trump-comjerusalem-passa-por-apoio-evangelico.shtml. Acesso em: 30 jun. 2019.

BARR, James. Beyond fundamentalism. Philadelphia: The Westminster Press, 1984.

BRASIL. Câmara dos Deputados. Ata da 91 a Sessão da Câmara dos Deputados, Deliberativa Extraordinária, Vespertina, da $2^{\text {a }}$ Sessão Legislativa Ordinária, da 55 ${ }^{a}$ Legislatura, 17 de abril de 2016. Disponível em:

https://www2.camara.leg.br/atividade-

legislativa/plenario/discursos/escrevendohistoria/destaque-de-materias/impeachmentda-presidente-dilma/sessao-091-de-170416. Acesso em: 16 out. 2019.

CALDAS, Carlos. Motivações teológicas da intenção do Governo Bolsonaro de mudar a embaixada do Brasil em Israel de Tel Aviv para Jerusalém. Revista IHU On-Line, São Leopoldo, 2 abr. 2019. Disponível em: http://www.ihu.unisinos.br/78-noticias/588021motivacoes-teologicas-da-intencao-do-governo-bolsonaro-de-mudar-a-embaixada-dobrasil-em-israel-de-tel-aviv-para-jerusalem. Acesso em: 30 jun. 2019.

CAMPOS, Breno Martins. A verdade ao pé da página: a Bíblia de Scofield e sua influência dispensacionalista no fundamentalismo protestante. In: ALMEIDA, Leandro Thomaz de (org.). Rostos do fundamentalismo: abordagens histórico-críticas. São Paulo: Terceira Via, 2017. p. 49-81.

CONCONE, Maria Helena Villas Boas. Pesquisa qualitativa nos estudos de religião no Brasil. In: SOUZA, Beatriz Muniz de; GOUVEIA, Eliane Hojaij; JARDILINO, José Rubens Lima (org.). Sociologia da religião no Brasil. São Paulo: PUC-SP; São Bernardo do Campo: UMESP, 1998. p. 125-136.

COUTINHO, João Pereira. Nada de novo debaixo do sol: para mim, ver um comprimido é como a promessa de um osso para um cachorro. Folha de S. Paulo, São Paulo, 4 set. 2018. Disponível em:

https://www1.folha.uol.com.br/colunas/joaopereiracoutinho/2018/o9/nada-de-novodebaixo-do-sol.shtml. Acesso em: 13 jun. 2019.

CUNHA, Magali. A hegemonia pentecostal no Brasil: como os evangélicos pentecostais passaram a dominar importantes espaços na política, no mercado e nas mídias. Cult: revista brasileira de cultura, São Paulo, v. 22, n. 252, p. 24-27, dez. 2019.

DUVIVIER, Gregorio. Já tivemos outro assunto. Que saudade de reclamar da tomada de três pinos. Folha de S. Paulo, São Paulo, 7 ago. 2019. Disponível em: https://www1.folha.uol.com.br/colunas/gregorioduvivier/2019/o8/ja-tivemos-outroassunto.shtml. Acesso em: 28 ago. 2019.

EVANGÉLICOS lamentam recuo de Bolsonaro ao anunciar escritório em Jerusalém. Pastor Silas Malafaia, porém, defendeu presidente ao dizer que "EUA levaram 9 meses para mudar embaixada”. Folha de S. Paulo, São Paulo, 1 abr. 2019. Disponível em: https://www1.folha.uol.com.br/mundo/2019/o4/evangelicos-lamentam-recuo-debolsonaro-ao-anunciar-escritorio-em-jerusalem.shtml. Acesso em: 29 jun. 2020. 
FACHIN, Patrícia. A admissibilidade do impeachment e o pragmatismo evangélico. Entrevista especial com Magali Cunha. Revista IHU On-Line, São Leopoldo, 28 abr. 2016. Disponível em: http://www.ihu.unisinos.br/entrevistas/554233-a-admissibilidadedo-impeachment-e-o-pragmatismo-evangelico-entrevista-especial-com-magali-cunha. Acesso em: 23 jun. 2020.

FERNANDES, Talita. Bolsonaro afirma que transferirá embaixada para Jerusalém até 2021. Governo abriu escritório de negócios na cidade após críticas de países árabes à mudança. Folha de S. Paulo, São Paulo, 3 fev. 2020. Disponível em: https://www1.folha.uol.com.br/mundo/2020/o2/bolsonaro-afirma-que-transferiraembaixada-para-jerusalem-ate-2021.shtml. Acesso em: 29 jun. 2020.

GIELOW, Igor. Bolsonaro deverá trocar embaixada por escritório em Jerusalém. Presidente havia feito promessa de mudança do local de representação diplomática, mas enfrentou resistências. Folha de S. Paulo, São Paulo, 28 mar. 2019. Disponível em: https://www1.folha.uol.com.br/mundo/2019/o3/bolsonaro-pode-trocar-embaixada-porescritorio-em-jerusalem.shtml. Acesso em: 10 jun. 2020.

GIELOW, Igor. Na primeira live, Bolsonaro usa Churchill contra acusação de fascismo: eleito tinha memórias do estadista, versão popular da Bíblia, Constituição e polemista à mesa. Folha de S. Paulo, São Paulo, 29 out. 2018. Disponível em:

https://www1.folha.uol.com.br/poder/2018/10/na-primeira-live-bolsonaro-usa-churchillcontra-acusacao-de-fascismo.shtml. Acesso em: 3 jul. 2019.

GIELOW, Igor. Netanyahu terá encontro com Bolsonaro no Brasil antes da posse. Premiê israelense deve ser recebido pelo presidente eleito no dia 28 de dezembro. Folha de $\mathbf{S}$. Paulo, São Paulo, 18 dez. 2018. Disponível em: https://www1.folha.uol.com.br/mundo/2018/12/netanyahu-tera-encontro-combolsonaro-no-brasil-antes-da-posse.shtml. Acesso em: 4 jul. 2019.

GIELOW, Igor. Premiê de Israel não deve mais ir à posse de Bolsonaro. Netanyahu, em crise política, era estrela do evento; encontro com eleito na sexta permanece. Folha de S. Paulo, São Paulo, 25 dez. 2018. Disponível em: https://www1.folha.uol.com.br/mundo/2018/12/premie-de-israel-nao-deve-mais-ir-aposse-de-bolsonaro.shtml. Acesso em: 4 jul. 2019.

KAMLER, Barbara; THOMSON, Pat. Trabalhando com literaturas. In: SOMEKH, Bridget; LEWIN, Cathy (org.). Teoria e métodos de pesquisa social. Petrópolis: Vozes, 2015. p. $45-55$.

KRESCH, Daniela. Cristãos sionistas substituem judeus de esquerda no apoio a Israel. Grupo tem recebido atenção crescente de políticos israelenses, principalmente no Brasil. Folha de S. Paulo, São Paulo, 25 jan. 2020. Disponível em: https://www1.folha.uol.com.br/mundo/2020/o1/cristaos-sionistas-substituem-judeusde-esquerda-no-apoio-a-israel.shtml. Acesso em: 10 jun. 2020.

MENDONÇA, Antonio Gouvêa. Uma macro-reflexão sobre o campo religioso brasileiro: variações sobre dois temas "bourdieuanos" - A propósito da morte de Pierre Bourdieu (23/01/02). Estudos de Religião, São Bernardo do Campo, v. 16, n. 23, p. 22-40, jul.dez. 2002. 
MERRITT, Jonathan. Compreender a obsessão evangélica com Israel. Revista IHU OnLine, São Leopoldo, 13 dez. 2017. Disponível em: http://www.ihu.unisinos.br/186noticias/noticias-2017/574575-compreender-a-obsessao-evangelica-com-israel. Acesso em: 30 jun. 2019.

MILLS, Charles Wright. A imaginação sociológica. 3. ed. Rio de Janeiro, 1972.

NETANYAHU diz que Bolsonaro se comprometeu a mudar embaixada para Jerusalém em 2020. Premiê deu declaração ao lado de Eduardo durante a inauguração de escritório comercial brasileiro na cidade. Folha de S. Paulo, São Paulo, 15 dez. 2019. Disponível em: https://www1.folha.uol.com.br/mundo/2019/12/com-presenca-de-netanyahu-brasilinaugura-escritorio-comercial-em-jerusalem.shtml. Acesso em: 10 jun. 2019.

PIERUCCI, Antônio Flávio. Fundamentalismo e integrismo: os nomes e a coisa. Revista USP, São Paulo, n. 13, p. 144-156, 1992. Disponível em:

http://www.revistas.usp.br/revusp/article/view/25620/27360. Acesso em: 3 out. 2017.

PONDÉ, Luiz Felipe. Três relatos ridículos: "coletivos" vigiam em festas o comportamento dos meninos que gostam de meninas. Folha de S. Paulo, São Paulo, 16 jul. 2018.

Disponível em: https://www1.folha.uol.com.br/colunas/luizfelipeponde/2018/o7/tresrelatos-ridiculos.shtml. Acesso em: 13 jun. 2019.

QUEIROZ, Christina. Fé pública: pesquisadores locais e estrangeiros buscam compreender crescimento evangélico no Brasil, o maior do mundo. Pesquisa FAPESP, São Paulo, v. 20, n. 286, p. 12-19, dez. 2019.

REINKE, André Daniel. O sionismo cristão e sua influência na cultura protestante brasileira. 2018. Dissertação (Mestrado em Teologia) - Faculdades EST, 2018.

SANTOS, Boaventura de Sousa. Na oficina do sociólogo artesão: aulas 2011-2016. São Paulo: Cortez, 2018.

SINGER, André. Jair Bolsonaro, até aqui, joga no escuro: eleito com uma plataforma vaga, ele agora será obrigado a tomar decisões. Folha de S. Paulo, São Paulo, 8 set. 2018. Disponível em: https://www1.folha.uol.com.br/colunas/andresinger/2018/12/jogandono-escuro.shtml. Acesso em: 23 jun. 2019.

SMITH, Robert O. Implicaciones interreligiosas del sionismo cristiano. Signos de Vida, n. 55, p. 28-35, mar. 2010.

WACHHOLZ, Wilhelm; REINKE, André Daniel. Pela paz de Jerusalém: a origem do sionismo cristão, sua influência na igreja protestante brasileira e sua atuação no Congresso Nacional. Revista Brasileira de História das Religiões, Maringá, v. 13, n. 37, p. 253273, mai.-ago. 2020. 